Revue bibliographique pour le domaine irano-aryen

\title{
Sepideh Qaheri, Julien Cuny. « Manches de miroirs égyptiens de Suse »
}

\section{Rémy Boucharlat}

\section{(2) OpenEdition}

10 Journals

\section{Édition électronique}

URL : http://journals.openedition.org/abstractairanica/48202

DOI : 10.4000/abstractairanica.48202

ISBN : 1961-960X

ISSN : 1961-960X

Éditeur :

CNRS (UMR 7528 Mondes iraniens et indiens), Éditions de l'IFRI

Référence électronique

Rémy Boucharlat, « Sepideh Qaheri, Julien Cuny. « Manches de miroirs égyptiens de Suse » ,

Abstracta Iranica [En ligne], Volume 40-41 | 2019, document 13, mis en ligne le 15 juillet 2019, consulté le 22 avril 2021. URL : http://journals.openedition.org/abstractairanica/48202 ; DOI : https://doi.org/ 10.4000/abstractairanica.48202

Ce document a été généré automatiquement le 22 avril 2021

Tous droits réservés 


\title{
Sepideh Qaheri, Julien Cuny. «Manches de miroirs égyptiens de Suse »
}

\author{
Rémy Boucharlat
}

\section{RÉFÉRENCE}

Sepideh Qaheri, Julien Cuny. « Manches de miroirs égyptiens de Suse », Revue

d'égyptologie 68, 2018, p. 253-259

1 Trois pièces en forme de massue, en fritte «bleu égyptien ", trouvées dans les fouilles anciennes de Suse, sans localisation précise, ont été interprétées jusqu'à une date récente comme des balustres d'escalier (longueur 20-22 cm). Familiers aux égyptologues, ces objets sont en fait des manches de miroirs circulaires qui étaient des disques en bronze ou en faïence encastrés dans une fente du manche. À côté de l'usage d'un accessoire de toilette, ces miroirs avaient aussi un rôle symbolique dans la liturgie des temples ou les pratiques funéraires. Les trois manches du Louvre apportent un nouveau témoignage sur la présence d'éléments égyptiens à Suse, qu'ils aient appartenus à des d'Egyptiens installés à Suse, ou qu'ils soient des objets importés pour des pratiques religieuses qui restent indéterminées. 


\section{AUTEURS}

RÉMY BOUCHARLAT

UMR 5133 CNRS-Université de Lyon 